\title{
Educational Intervention for the Prevention of Falls in Older Adults of Office Number 41
}

\author{
Ana Olivia Ramos Rodríguez ${ }^{1 *}$, Manuel Enrique Guerra Tórrez², Sahirys González Piloto³, Yem \\ Agustín Mato Ramos ${ }^{4}$ and Dra Belkis Verga Tirado ${ }^{5}$ \\ ${ }^{1}$ Segundo Gradoen Medicina General Integral, Filial de Ciencias Médicas Manuel Piti Fajardo, San Cristóbal, Cuba \\ ${ }^{2}$ Primer Gradoen Medicina General Integral, Policlínico Santa Cruz, San Cristóbal, Cuba \\ ${ }^{3}$ Primer Gradoen Medicina General Integral y Oftalmología, Policlínico Camilo Cienfuegos. San Cristóbal, Cuba
}

${ }^{4}$ Especialista de Primer Grado en Cirugía General, Hospital General Docente Comandante Pinares. San Cristóbal, Cuba

${ }^{5}$ Segundo Grado en Medicina General Integral, Centro Municipal Higiene y Epidemiología. San Cristóbal, Cuba

*Corresponding author: Ana Olivia Ramos Rodríguez, Segundo Grado en Medicina General Integral, Filial de Ciencias Médicas

Manuel Piti Fajardo, San Cristóbal, Cuba

\section{ARTICLE INFO}

Received: 幽 December 22, 2020

Published: 慧 January 06, 2021

Citation: Ana Olivia Ramos Rodríguez, Manuel Enrique Guerra Tórrez, Sahirys González Piloto, Yem Agustín Mato Ramos, Dra Belkis Verga Tirado. Educational Intervention for the Prevention of Falls in Older Adults of Office Number 41. Biomed J Sci \& Tech Res 33(1)-2021. BJSTR. MS.ID.005334.

Keywords: Chronic periodontitis; Cardiovascular disease; Systemic inflammation; Cholesterol; C-reactive protein; Matrix metalloproteinases

\section{ABSTRACT}

Introduction: As you get older, you are predisposed to the occurrence of accidents, among them falls, responsible for deaths, disorders and sequelae in individuals and families.

Objective: To validate an educational strategy for the prevention of falls aimed at older adults belonging to medical office 41 of the Santa Cruz health area.

Method: An educational intervention was carried out, which consists of instructing the elderly and caregivers on the subject and the investigation of risk factors present in the home, in the period from October 2017 to May 2019. The universe was made up of 39 older adults dispensed, and the sample with those who met the inclusion criteria. The variables of interest were identified through individual and family medical records. Through a final interview, satisfaction with the program implemented and the modification of these factors in the dwellings were evaluated. Statistical methods such as chi-square were used to determine the association of variables as well as Mc Nemar for the efficacy of the intervention.

Conclusion: The highest percentage of patients was comprised between the groups of 70 and 79 years, predominantly male. Most of the elderly were independent, and more than half had a history of falls. The vast majority presented a decrease in visual acuity as a cause associated with falls. Cardiovascular diseases predominated. Following the strategy, it was possible to reduce both extrinsic risk factors for falls and unsafe conditions.

\section{Introduction}

Aging is a natural event that involves a certain number of anatomical, physiological, psychological and social changes in the individual's organism, but also with broad social repercussions; it does not constitute a simple or unitary process, but rather a bundle of processes associated with each other [1]. Demographic aging is a population phenomenon that has occurred throughout the world, the number of people over 60 years of age has risen from just over 400 million in 1950 to 700 million today, in 2000 the world population of The elderly was 578 million, with a forecast of more than 1200 million for 2025, it is expected that by the year 2050 it will be 1,420 million, that is, it will grow annually at a rate of $2.5 \%$ compared to the total world population that it only grows $1.7 \%$ [2]. It has occurred in the Cuban population since the twentieth century. At the beginning of it, there were around 72,000 people over 60 years of age; However, in 1950 the figure exceeded 425,000, in 1990 the country had more than 1.2 million elderly 
people. Decennial growth is estimated at around 250,000 until the year 2000 and after this year, growth of more than 400,000 is expected until 2025 [3]. The presence in Cuba of more than 1.8 million elderly people, implies not only a simple increase in the proportion, but establishes the absolute increase of a social group with its own characteristics, its existence must be considered as an extraordinary social achievement, but also at the same time, it implies a challenge, that of a healthy old age that has ceased to be an exception and a privilege to become an opportunity in countries like ours, with a life expectancy that exceeds 77 years and programs that aim at a quality of life progressively better, being essential to know the health status of this sector, as well as its demands [4]. It is expected that in 2019 fewer people will arrive of working age and more will retire, with a substantial expenditure on social security, therefore that it is necessary to design health strategies for sciences such as Geriatrics $[4,5]$.

Aging has general characteristics within the geriatric clinic: Atypical presentation of diseases, aging of organs and systems, deterioration of the senses, inadequate information from family members, little functional reserve and great repercussion in the social and family environment, therefore requires a solid culture of satisfying longevity, which dismantles myths and irrational ideas incompatible with full life in old age, acquires habits and behaviors that preserve their physical and mental well-being, and structures more human and realistic needs and motives with relation to their health and take responsibility for their own aging [5]. Accidents in general represent a growing health problem worldwide, with the elderly being a vulnerable group and multifactorial causes of accidents due to falls in the elderly. They can be: intrinsic when they are capable of causing alterations in the osteomyoarticular, cardiovascular, psychological, neurological, gastrointestinal and other systems; or extrinsic when they are due to conditions inside and outside the home such as uneven floors, inadequate lighting, defective stairs, wet or slippery floors, among others [6]. Our state maintains the premise of providing attention to the study and implementation of strategies in all sectors of society to face the high levels of aging of the population and raise the quality of the service provided, in order to achieve the satisfaction of the population and minimize the factors related to falls in the home of the elderly (AM), which imposes a challenge to research, teaching and care performance [7].

\section{Problem Statement}

What results does the execution of an educational intervention for the prevention of falls in older adults at the 41 Family Medical Clinic of the Santa Cruz health area, San Cristóbal Municipality offer?

\section{Justification of the Problem}

The aging of the Cuban population is identified as an event in full swing. According to the 2015 National Yearbook of Health Sta- tistics, $19.20 \%$ of people are 60 years old and over [8]. The Artemisa Province, for its part, shows a population aging index of 17.1 [8] The annual accident rate in the country for all ages is 48.3 , in the case of Artemisa province it increases to 48.7, with 4020 deaths reported in those over 60 years of age with a rate that reaches 191.6 and specifically for those over 80 years of age it is 771.9, that is, it increases the death rate from accidents by almost 15 times for all ages [8]. Of this total number of accidents, 2,460 were due to falls, this being the main cause during 2015 with a rate of 21.9 [8]. In the case of San Cristóbal, our population shows a notable increase in the number of people over 60 years of age $(15,436)$, reaching a Roset index (population aging) of 20.76, an indicator that is above the national average (19.0) [9]. Deaths from accidents, even though it decreases in 5 cases and the rate decreases to 27.9, it remains the fourth cause of death in the municipality [9]. The Santa Cruz health area has a total of 4099 elderly people and in the Office, Doctor Number 41, we found 39 patients over 60 years of age who represent $13.4 \%$ of the general population [10]. Due to this problem, we set ourselves the following objective: To determine the results of an educational intervention for the prevention of falls in older adults belonging to the Family Medical Office Number 41, of the Santa Cruz health area, during the period October 2017 to May 2019.

\section{Methods}

Type of study. An intervention study was carried out on the investigation of risk factors for falls, based on an educational strategy aimed at older adults and caregivers belonging to the 41 family doctor's office of the Santa Cruz Polyclinic in the period from October 2017 to May 2019 The universe consisted of 39 patients over 60 years of age and their caregivers. The sample was made up of those patients older than 60 years dispensed in the family medical office number 41 who expressed their willingness to participate, with physical and mental capacities to answer the questionnaires, who managed to participate in $60 \%$ of the planned activities both elderly as caregivers. The variables selected for the study were collected from the individual and family medical history and in a direct interview with the patient and by observing the physical environments of the house and its exteriors (Appendix 1).

Main or primary variables: Those that are related to the results of the intervention:

1. Modification of risk factors for falls in households before and after the intervention

2. Non-main variables: Those that allowed characterizing the study group, its support networks and living conditions and identifying the risk factors for falls present before the intervention

\section{Methods and Procedures}

Collection of Primary Data: They proceeded to obtain their consent to participate in the work (Appendix 1) To form the 
primary data that was recorded in the data sheet (Appendix 2), the general data of the patient, the diseases suffered, their support networks and personal history of falls. The functional evaluation was carried out by applying the Geriatric Functional Evaluation Scale, which made it possible to evaluate the sensory limitations that constitute risk factors for these events (Appendix 3). In addition, in the context of this visit to the family, an observation guide was applied to identify extrinsic risk factors for falls in family settings (Appendix 4) The second phase in the execution of the project consisted of the application of an educational intervention strategy aimed at older adults and their caregivers in order to modify the risk and prevent accidents due to falls, following the program provided in Appendix 5 This strategy proposes a program of educational and assistance actions aimed at controlling the risk factors for falls in older adults, promoting the development of healthy environments as well as the preparation of support networks for the elderly with a risk approach, the guidelines for personalized way and taking into account the identified risks. The results of the intervention were evaluated through the application of the initial observation guide and the evaluation of the control of extrinsic risk and those intrinsic that were modifiable, which constituted an indirect indicator of the explicit intention to eliminate the risk of falls and controlling your risk factors (Appendix Table 1).

\section{Information Processing}

We used statistical methods for qualitative variables, chi-square to determine the association of variables and statistical significance, as well as Mc Nemar to evaluate the efficacy of the intervention. The results were processed manually with a calculator, using a Pentium IV PC with a Windows XP program. The texts were processed with Word XP, the tables and graphics were made in Excel XP. The results obtained are shown in contingency tables and graphs using absolute numbers and percentages as a summary measure.

\section{Ethical Aspects}

This research was adjusted to the recommendations contained in the Declaration of Helsinki 1989, respecting the voluntary nature and the right of people to participate or leave the study at the time they consider it respecting their will. After applying the survey and the questionnaire, the consent of the person was requested in writing (Appendix 1), with the guarantee of anonymity and confidentiality of the data collected in the forms (Table 1). The highest percentage of the patients that made up our sample was between the 70 and 79-year-old groups, representing 48.7, but this differs from what was observed in the general population of the municipality, 9 with a predominance of males (54.1\%), while the female sex represented $45.9 \%$. However, when looking for a relationship between the two variables, no significant (Table 2) differences were found. Most of the elderly were independent in their evaluation, $86.5 \%$ of them, which constitutes an interest of the program for the elderly in Cuba (Table 3). As illustrated in the table, 20 elderly people in the sample (54.05) had a history of falls with physical and mental sequelae. The fall is a frequent event in the elderly that, on certain occasions, is of special importance and should always be a cause for concern (Table 4). It is shown that in 94.6 of the cases, the decrease in visual acuity was manifested in the elderly who suffered falls, to constitute the most prevalent associated cause (Table 5). In the study of the history of diseases, it was found that the highest percentage was cardiovascular diseases with $43.2 \%, 24.3 \%$ were associated with other causes that, although not differently collected in the survey, bone diseases were referred to as frequency (Tables 6). There are several factors that can contribute to the fact that the fall is more frequent in the elderly, they are divided into two large groups, the intrinsic ones that depend on the person and can be chronic in nature and the extrinsic ones that depend on the environment, which are refers to Table 6, which shows that before the intervention, only $3.2 \%$ of the elderly did not present any risk factor, which increases at the end of the educational strategy to $89.1 \%$, of the 12 elderly who presented unsafe conditions without The need for resources was reduced to $8.1 \%$, persisting $2.7 \%$ of the elderly with unsafe conditions due to the need for resources.

Table 1: Distribution of the sample according to age.

\begin{tabular}{|c|c|c|c|c|c|c|}
\hline \multirow{2}{*}{ Age groups } & \multicolumn{2}{|c|}{ Male } & \multicolumn{2}{c|}{ Female } & \multicolumn{2}{c|}{ Total } \\
\cline { 2 - 7 } & No. & $\%$ & No & $\%$ & No & $\%$ \\
\hline $60-69$ & 7 & & 8 & & 15 & 40,5 \\
\hline $70-79$ & 10 & & 8 & & 18 & 48.7 \\
\hline $80-89$ & 3 & & 1 & & 4 & 10.8 \\
\hline 90 or more & & & & & & \\
\hline Total & 20 & 54,1 & 17 & 45,9 & 37 & 100 \\
\hline
\end{tabular}

Table 2: Behavior of the Functional Assessment.

\begin{tabular}{|c|c|c|}
\hline Cardiovascular risk & No. & \% \\
\hline Independence & 32 & 86.5 \\
\hline Partial dependency & 4 & 10.8 \\
\hline Total dependency & 1 & 2.7 \\
\hline Total & 37 & 100 \\
\hline
\end{tabular}

Table 3: Behavior of the antecedents of falls and their consequences.

\begin{tabular}{|c|c|c|}
\hline Background & No. & \% \\
\hline Falls without physical damage & 9 & 24,3 \\
\hline Falls with affectations that required medical attention & 7 & 18,9 \\
\hline $\begin{array}{c}\text { Falls with affectations that required medical - surgical } \\
\text { attention }\end{array}$ & 4 & 10,8 \\
\hline Falls with physical or mental consequences & - & - \\
\hline Total & 20 & 54,05 \\
\hline
\end{tabular}

Table 4: Behavior of Changes associated with aging.

\begin{tabular}{|c|c|c|}
\hline Changes associated with aging & No & \% \\
\hline Decreased visual acuity & 35 & 94.6 \\
\hline Decreased accommodation & 12 & 32.4 \\
\hline Decreased sensory recognition & 4 & 10.8 \\
\hline
\end{tabular}




\begin{tabular}{|c|c|c|}
\hline Oscillating gear & 2 & 5.4 \\
\hline Total & 37 & 100 \\
\hline
\end{tabular}

Table 5: Behavior of personal history of illness.s.

\begin{tabular}{|c|c|c|}
\hline Personal history of illness & No. & $\%$ \\
\hline Neurological diseases & 5 & 13.5 \\
\hline Cardiovascular & 16 & 43.2 \\
\hline Psychiatric & 2 & 5.4 \\
\hline Other & 9 & 24.3 \\
\hline
\end{tabular}

Table 6: Extrinsic risk factors for falls in the home or its surroundings before and after the intervention.

\begin{tabular}{|c|c|r|c|c|}
\hline \multirow{2}{*}{$\begin{array}{c}\text { Extrinsic risk factors for falls in or around } \\
\text { the home }\end{array}$} & \multicolumn{2}{|r|}{ Before } & \multicolumn{2}{|c|}{ Then } \\
\cline { 2 - 5 } & No & $\%$ & No & $\%$ \\
\hline It does not present any risk factor & 16 & 43,2 & 33 & 89,1 \\
\hline $\begin{array}{c}\text { Unsafe conditions easily solved without } \\
\text { the need for resources }\end{array}$ & 12 & 32,4 & 3 & 8,1 \\
\hline $\begin{array}{c}\text { Unsafe conditions difficult to solve due to } \\
\text { the need for resources }\end{array}$ & 9 & 24,3 & 1 & 2,7 \\
\hline Total & 37 & 100 & 37 & 100 \\
\hline & & & \\
\hline
\end{tabular}

\section{Discussion}

The geriatric population nationally and internationally is characterized by a greater number of female representatives 5,6 and by the decrease of this as age advances and life expectancy is exceeded, which in Cuba is around 77 years.3 Similar behavior is observed in other studies, 1 In a study carried out by Fu AZ, the age group that predominated is 65-69 years, [11] which coincides with studies carried out in this regard in Cuba, [12] when studying the behavior of population groups, we can explain this scientifically, by the development that Geriatrics has reached in Cuba, with its community projection, reaching a higher life expectancy each year, reaching a greater number of adults, reaching the elderly. We have reviewed similar results in the international bibliography. Eleven The International Research Center in the United States reported that the demographic behavior of the population over 60 years of age in more than 30 countries was in favor of the female sex, prevailing generically in relation to males, [13] arguing these results for the direct effect of the favorable living conditions and socioeconomic well-being in which women live, as well as the influence of risk factors such as smoking and alcohol that have a greater incidence in men, and that their negative effect on the health of the individual has been demonstrated. Other scholars on the subject are based on the incidence of malignant diseases is higher in men than in women, which has justified the inversion of the population pyramid in terms of gender, with a predominance of the female sex after 60 years. The greatest concern of women for their health and for estrogenic protection has also been raised [14].

The validity for daily activity observed in our subjects is high and is equivalent to that found in other studies in our country [15]. subjects do not need any help and most older people can use their daily routine to solve their physiological, hygiene and personal care needs, make visits, go up and down stairs or stay alone at night, they can make their food and wash or iron your clothes without difficulties; They are capable with the purchase of errands and manage without requiring help [16] In other research, the same results are not observed since the elderly, suffering from chronic diseases adds to the aging process itself and the social situation in which they live, as the population ages, the prevalence of disabling chronic diseases increases and makes them fragile and dependent $[17,18]$ The main immediate consequence of falls is fracture, from 2 to $10 \%$ of the elderly who fall suffer fractures, the hip fractures are the most important for the elderly, since as a complication it can lead the elderly to immobilization with all its complications and even death. $5 \%$ of the elderly fall suffer serious tissue damage that requires hospitalization. (One in 40), in those who live alone, prolonged stay on the floor due to blocking of the labyrinthine righting reflex can cause dehydration. It is necessary to bear in mind the cranioencephalic and thoracic trauma that can occur with its possible complications [19]. The incidence and severity of fall complications increase with age, as well as in institutionalized elderly, compared to those who live at home. The etiology of falls is multifactorial in nature, making it difficult to detect a primary cause in most cases. Other studies agree with these results [20].

Approximately $30 \%$ of those over 65 in the community fall at least once a year, this frequency can increase to $50 \%$ for those over 80 years of age. It is necessary to bear in mind that half of those who fall repeat it, by sex women suffer twice as many falls as men, although this proportion levels off after 75 years. Altogether $3 / 4$ parts of falls occur at home, approximately $1 / 3$ of falls are due to the environment in which the elderly person lives [21]. The incidence of falls in hospital units is 1.5 per bed per year, closely related to medication and the underlying disease. The incidence of falls in institutions is 2.0 falls per bed and per year, $50 \%$ of institutionalized elderly suffer falls at some point during their stay in the institution $5 \%$ of elderly people who fall require medical attention, we cannot forget that the most common cause of accidental death in the elderly is falls [22]. The elderly fall easier because they progressively lose the ability to maintain balance, with aging, part of the reflexes that maintain posture are altered and this is how some elderly lose their balance, they are unable to maintain the center of gravity with changes positionalists cannot perform rapid adaptation movements. In the elderly, all these mechanisms are altered, producing an alteration of the normal gait pattern as the regulatory mechanisms of muscle tone also deteriorate. Podiatric problems also predispose to falls. 21

In relation to the changes associated with aging, other cases reveal that in $20-25 \%$ of falls it is necessary to consider orthostatic hypotension, which is usually asymptomatic, there are several situations in which it can be symptomatic (situations of low cardiac output, dysfunction of the autonomic nervous system, impaired venous return, stay in bed and use of certain drugs. 
Syncope causes $1 \%$ of falls. $50 \%$ of them are of cardiovascular origin. Arrhythmias only cause syncope and falls when associated with alterations in cerebral blood supply. Other cardiac causes include atypical acute myocardial infarction, hypertrophic cardiomyopathy, and aortic stenosis. Causes of vasovagal syncope, increased vagal tone with bradycardia, and hypotension include cough, urination, hyperventilation, and defecation $[3,4]$. Other studies report that the most frequent home accidents are falls, burns and intoxications, where falls and fractures can cause a serious deterioration in the quality of life of the elderly. Among the factors that increase your risk are: lack of physical activity, which favors decalcification of the bones (osteoporosis), loss of agility, and loss of cardiac and respiratory capacity [23,24]. Other causes such as consumption of alcohol and sedatives decrease attention to obstacles and increase recklessness and imbalance [25]. When reviewing the literature regarding non-communicable chronic diseases, it is suggested that bone degenerative changes are the result of aging, which is why they constitute the most referred conditions, and associated with frequent falls. 7 in other studies such as those of Liliam Gretel Cisneros obtained the primacy for arterial hypertension [26]. Other research reports that the most common diseases are osteomyoarticular diseases, osteoarthritis, gait and balance disorders, Cerebrovascular Disease (CVA), Parkinson's disease, cancer and chronic pain $[27,28]$.

Seife M considers that chronic disorders or diseases vary from relatively benign ones, such as a partial loss that can be hearing, visual, to serious diseases such as cancer, cardiovascular diseases, diabetes, musculoskeletal diseases and even more alarming from the point of view From a statistical point of view, the greatest number of people will develop some type of disability or chronic disease that can become the cause of death. Most chronic diseases affect important aspects of life in people who have them. One of the main changes and perhaps the one that generates the greatest deterioration is the emotional aspect, since the person is necessarily forced to a rapid adaptation process for which they go through different stages that arouse a series of commonly negative emotions (fear, anger, anxiety) [27]. The changes produced by aging and chronic diseases that the elderly present are the main intrinsic causes of falls. Central nervous system diseases such as Parkinson's disease, dementia, strokes, confusional states, labyrinthine disorders, seizures, and peripheral neuropathy predispose to falls. The most frequent cardiovascular risk factors are arrhythmias, syncope, orthostatic hypotension, and myocardial infarction [29]. Many authors argue that drugs play an important role in the etiology of falls, since many elderly take 1 or more drugs than per different mechanisms can cause falls such as sedatives, hypnotics, hypoglycemic agents, diuretics, alcohol [30,31].

In today's world it is a proven fact that as life expectancy increases, frailty rates and the prevalence of chronic diseases increase, aspects that accompany the last stretch of life [32]. It is therefore expected that a most of the older adults are frail and also suffer from chronic diseases [33-35]. Recent epidemiological studies document this association. Such is the case of a crosssectional study carried out in 740 older adults in a community of Santiago de Chile that analyzed the relationships between frailty, comorbidity and disability, the results of which revealed that $7.4 \%$ met Fried's criteria for frailty, of which $81.8 \%$ had associated chronic diseases and $29.1 \%$ had disabilities for activities of daily living [36]. The main extrinsic factors for falls inside the home are usually floors soaked by water or urine, polished floors, abandoned toys, pets, poor or intense lighting, carpets, lack of auxiliary bars in the bathroom, Stairs without handrails poorly lit with very high or worn steps. Falls also occur frequently in recent days after being admitted to the hospital or a residence, when we go for a walk through the unevenness of the floors, gaps and all the architectural barriers that exist [37]. The most dangerous places in the house are the bathroom and the kitchen; in the first, falls are suffered when slipping, when entering or leaving the shower, in the second, burns. Small and stagnant furniture, lack of light, small rugs that can slip also influence; shoes without caps [38]. We must individualize all the extrinsic and intrinsic factors that could influence the fall, taking into account the multifactoriality of the fall, it is necessary to draw up a plan to prevent them, assessing and treating the intrinsic risk factors, assessing and eliminating the extrinsic factors, and analyzing the circumstances in which the fall occurred. The success of the treatment of falls lies in its prevention and the fundamental link is in the home and the community $[39,40]$. From the social point of view, the family abruptly breaks its usual functional harmony with work, home, psychologically the great anxiety that the elderly person may fall down again, and overprotection is making the elderly increasingly dependent, a high Afterwards, a number of these elderly need institutionalization in assisted residences because the family is not able to take care of them, so accidents can be avoided with caution, special supports must be installed, order and good lighting in the house can prevent them $[41,42]$.

With the increase in life expectancy and the decrease in mortality, new social scenarios have been generated in which the coexistence of different generations in the same territory can be appreciated; this coexistence does not always translate into a positive link of communication and understanding. The different generations can already be found in family nuclei, in the coexistence of the same space as a home, but they cannot effectively be a bond based on the solidarity paradigm. In other cases, older adults may no longer live close to their family networks, they are in residences where ties must be forcibly established with other older adults in the same situation or in unfavorable conditions, where communication is seen reduced between the staff in charge of the caregiver work and the older adult himself. Therefore, the main objective of the educational strategy is to provide a collaborative learning space through the development of cognitive and social skills that contribute to the prevention of falls through the identification and 
elimination of risk factors effectively among the family. , society and older adults, with learning applicable to other dimensions [43].

\section{Conclusion}

The highest percentage of the patients that made up our sample was comprised between the groups of 70 and 79 years, with a predominance of males. Most of the elderly were independent in their evaluation, and in just over half there was a history of falls. The vast majority presented a decrease in visual acuity as a cause associated with falls. Cardiovascular diseases predominated as antecedent. Following the strategy, both extrinsic risk factors for falls and unsafe conditions were reduced.

\section{References}

1. González Rodríguez Raidel (2015) Falls in the home of the elderly: challenge for Cuban society. Rev Cubana Med Gen Integr [Internet] $31(2)$.

2. Camarero Forteza O (2013) Quality of life and social support in the elderly [thesis]. University of Havana.

3. Álvarez González K, Delgado Cruz A, Naranjo Ferregut JA, Pérez Martín MM, Valdés del Pino AM (2012) Functional evaluation of the elderly in the community. Rev Medical Sciences 16(2): 124-137.

4. Vega Restrepo T (2013) Functional evaluation of the elderly. II Part Geriatric Magazine 12(2): 31-34.

5. Mc Donald VM, Simpson JL, Higgins I, Gibson PG (2011) Multidimensional assessment of older people with asthma and COPD: clinical management and health status. Age Ageing 40(1): 42-49.

6. Cooper R, Kuh D, Cooper C, Gale C, Lawlor D, et al. (2011) Objective measures of physical capability and subsequent health: a systematic review Age Ageing 40(1): 14-23.

7. Baños I, Vidal A, Estrada C (2003) Attention to injured by accidents of $0-14$ years in the municipality of Matanzas. 1998-2000. Rev Méd Electronics 4(1).

8. (2018) Ministry of Public Health, Directorate of Medical Records and Health Statistics, 2017 Statistical Yearbook of Health. Havana.

9. Basic Health Chart. San Cristóbal Municipality.

10. Analysis of the health situation of the CMF 41.

11. Fu AZ, Qiu Y, Radican L, Luo N (2011) Marginal differences in healthrelated quality of life of diabetic patients with and without macrovascular comorbid conditions in the United States. Qual Life Res 20(6): 825-832.

12. Álvarez Sintes R (2014) Care for the elderly. In: Álvarez Sintes R. Integral General Medicine. Vol II. Health and Medicine. ( $3^{\text {rd }}$ Edn). Havana: Ecimed pp. 488-491.

13. Canevelli M, Grande G, Lacorte E, Quarchioni E, Cesari M, et al. (2016) Spontaneous Reversion of Mild Cognitive Impairment to Normal Cognition: A Systematic Review of Literature and Meta-Analysis. Journal of the American Medical Directors Association 17(10): 943948.

14. Paumier Rodríguez I, Rondón Peña MO, Hernández Ramírez GR, Montero Plumier IM, Gainza González B (2014) Educational intervention program to prevent accidents in mothers with children under five years of age. Multimed 18(3).

15. (2017) Pan American Health Organization. Regional Office of the World Health Organization. Guide for the Diagnosis and Management of Frailty. Part II.

16. (2017) Espín Andrade AM, Leyva Salermo B, Vega García E. How to take better care of ?. Self-Employed Caregiver Handbook.
17. Hernández Barea I, Cruz Torres W, Rodríguez Alarcón NM, Gutierrez Aguilera N (2011) Efficacy of Tai Chi Chuan in the prevention of falls in the elderly.

18. Romero Cabrera AJ (2012) Clinical assistance to the elderly. (2 ${ }^{\text {nd }}$ edn.). Havana: Ecimed.

19.SEPIN (2015), "Resource 846/2014. Speaker: IGNACIO SANCHO GARGALLO, TS, First Chamber, Civil, 244/2015, May 13”, Madrid, Editorial Jurídica SEPIN.

20. (2016) Colombian Journal of Cardiology, Print version ISSN Knowledge of the risk of presenting a myocardial infarction and the barriers to access to a healthy lifestyle, 0120-5633Rev. Colomb. Cardiol 23(3).

21. Scheil-Adlung X. (Eds.) (2015), "Global evidence on inequities in rural health protection: New data on rural deficits in health coverage for 174 countries", ESS Document, № 47, Organización Internacional del Trabajo (OIT).

22. Selman-Houssein E (2012) Centennials in Cuba. The secrets of longevity, Havana, Institute for Research on Longevity, Aging and Health (CITED), Aquarium Publications, Centro Félix Varela.

23. (2012) SiiS (Centro de Documentación y Estudios) "The home help service in a context of economic crisis. Main trends in Europe".

24. Tejada Ortiz BR, Giron Aguilera GL, Bernal Sánchez R (2011) Population aging in Cuba and its impact on society. Retrieved February 15.

25. (2016) South Africa, Government of "Social benefits".

26. (2013) Risk factors for ischemic heart disease, Dra. Liliam Gretel Cisneros Sánchez, Dr. Ediunys Carrazana Garcés, Institute of Cardiology and Cardiovascular Surgery. Havana Cuba Rev Cubana Med Gen Integr $29(4)$

27. Seife M, Valdés, L. Behavior of chronic diseases in the CITED Rehabilitation Service.

28. José Antonio González Pompa (2013) Risk factors for the occurrence of acute myocardial infarction in smokers, Revista Cubana de Salud Pública, Rev Cubana Salud Pública 39(4).

29. D’Art P, Katona P, Mullan E (1994) Screening, detection and management of depression in elderly primary care attenders: The acceptability and perfomance of the 15-item geriatric depression scale (GDS 15) and the development of shorter versions. Fam Pract 11(6): 260-266.

30. Menéndez J, Guevara A (2005) Enfermedades Crónicas y limitación Funcional: estudio comparativo de siete ciudades de América Latina y el Caribe. Revista Panameña de Salud Pública 17(5/6): 353-361.

31. (2016) Dirección Nacional de Registros Médicos y Estadísticos de Salud. Anuario Estadístico de la Salud 2014. La Habana: Ministerio de Salud Pública.

32. Mayordomo T, Sales A, Satorres E, Blasco C (2015) Estrategias de Afrontamiento en Adultos Mayores en Función de Variables Sociodemográficas. Escritos de Psicología 8: 2632.

33. (2015) World Health Organization [WHO]. World Report on Ageing and Heath.

34. (2014) World Health Organization [WHO]. Facts about ageing.

35. Rubio E, Comín M, Montón G, Martínez TY Magallón R (2015) Family care provided by the elders of a rural area to different generations. Gerokomos 26(2): 48-52.

36. Rosell J, Herrera S, Fernández, B y Rojas (2017) Chile y sus mayores: 10 años de la Encuesta Calidad de Vida en la Vejez UC Caja Los Andes. Resultados IV Encuesta Calidad de Vida en la Vejez. Santiago de Chile: Pontificia Universidad Católica de Chile.

37. Orosa Fraiz T (2003) La Tercera Edad y la Familia, una mirada desde el adulto mayor. Habana: Felix Verela.

38. Thumala DA (2015) Inclsuion y Exclusion social de las personas mayores en Chile. Santiago: Servicio Nacional del Adulto Mayor. 
39. Peña Casanova J (2014) Perfiles Cognitivos y Neuroimagen en el Deterioro Cognitivo Leve y la Enfermedad de Alzheimer. Presentación en las Jornadas de Actualización en Neuropsicología: Diagnóstico Diferencial de las Demencias, COPRAD. Chile

40. Thumala DA (2015) Inclsuion y Exclusion social de las personas mayores en Chile. Santiago: Servicio Nacional del Adulto Mayor.

41. (2002) Observatorio de Derechos Humanos de las Personas con Discapacidad Mental (2014). Derechos Humanos de las Personas con

ISSN: 2574-1241

DOI: 10.26717/BJSTR.2021.33.005334

Ana Olivia Ramos Rodríguez. Biomed J Sci \& Tech Res

(C) (i) This work is licensed under Creative Commons Attribution 4.0 License

Submission Link: https://biomedres.us/submit-manuscript.php
Discapacidad Mental: Diagnóstico de la Situación en Chile. Santiago, Chile. Organización Mundial de la Salud.

42. Alexopoulous GS (2009) Depresión y otros trastornos en el estado de ánimo. En: Geriatric Review Syllabus 3: 133-139.

43. Pereira J, Peñaranda D, Reyes A, Caceres K, Cañizarez Y (2015) Prevalence of cardiovascular risk factors in Latin America: a review of the published evidence 2010- 2015. Rev Mex Cardiol 26(3): 125-139.

$\begin{array}{ll}\text { BIOMEDICAL } & \text { Assets of Publishing with us } \\ \text { RESEARCHES } & \text { - Global archiving of articles } \\ \text { - Immediate, unrestricted online access } \\ \text { ISSN: 2574-1241 }\end{array}$

